\title{
DESENVOLVIMENTO DE VIDEIRA “NIAGARA ROSADA" PODADA EM DIFERENTES ÉPOCAS
}

\author{
Lourival Carmo Monaco Neto ${ }^{1}$, João Alexio Scarpare Filho ${ }^{1}$ \\ ${ }^{1}$ Escola Superior de Agricultura “Luiz de Queiroz”- Universidade de São Paulo. lcmonaco@gmail.com, jascarpa@usp.br
}

\section{RESUMO}

A cultura da videira Niagara Rosada apresenta grande importância em diferentes regiões produtoras, principalmente no estado de São Paulo. Para a produção dessa uva é fundamental a utilização da técnica cultural da poda, que pode ocorrer em diferentes épocas. Dessa forma o presente estudo teve como objetivo comparar o desenvolvimento da videira Niagara rosada podada em diferentes épocas através da análise das características: comprimento dos ramos e velocidade média de crescimento de ramos. As épocas de poda adotadas foram de inverno, com realização em 04/08/2010 e de verão, com realização em 28/01/2011. O delineamento estatístico utilizado foi o de blocos ao acaso com entre 7 e 8 unidades experimentais cada, totalizando 30 unidades. Cada bloco foi uma planta e a unidade experimental foi um ramo. Para a análise da variância foi empregado o teste de Tukey para comparar os tratamentos de poda de inverno e poda de verão. As variáveis foram comparadas em relação aos períodos do ciclo produtivo: Poda à Colheita, Brotação à Colheita, Poda à Brotação, Brotação ao Florescimento, Florescimento ao Início da Maturação dos frutos e Início da Maturação dos Frutos à Colheita. Houve resultado significativo em todas as comparações entre os tratamentos, de forma que se confirmou que em relação ao tamanho dos ramos, a poda de inverno apresentou ramos mais compridos do que a poda de verão. Em relação à velocidade média de crescimento dos ramos, esta foi superior na poda de inverno do que observada na poda de verão.

Palavras-chave: Uva, Poda de Inverno, Poda de Verão, Fisiologia

\section{DEVELOPMENT OF THE "NIAGARA ROSADA" VINE PRUNED AT DIFFERENT SEASONS}

\section{ABSTRACT}

The importance of the "Niagara Rosada" crop is major in several regions, especially in the state of São Paulo. In the production of this vine tree the use of pruning is essential, which can occur in several seasons. With that in mind, this study has as objective to compare 'Niagara Rosada' vine tree's development under different pruning seasons by analyzing characteristics as the length of the branch and average branch growth velocity. The adopted pruning seasons were the winter pruning, being done in 08/04/2010, and the summer pruning, being done 01/28/2011. As experimental plot were use 4 plants, with 7 or 8 branches each, with the total of 30 branches. To analyze the results one used the Tukey test, comparing the treatments in the different periods of the production cycle (Pruning to Harvest, Sprout to Harvest, Pruning to Sprout, Sprout to Flowering, Flowering to Early Ripening and Early Ripening to Harvest). There was a significant difference between the treatments in all the comparisons. For the length of the branches, the winter pruning showed longer branches in all the periods than the summer pruning. As for the average branch velocity, it was superior in all the periods in the winter pruning.

Key words: Vine, winter pruning, summer pruning, phisiology 


\section{INTRODUÇÃO}

$\mathrm{O}$ consumo brasileiro de uva in natura tem crescido nos últimos anos; passando de 0,58 kg.hab- ${ }^{1}$.ano- ${ }^{1}$ em 2002 para 0,76 kg.hab- ${ }^{1}$.ano- ${ }^{1}$ no ano de 2008 (SILVEIRA et al., 2011). Esse aumento no consumo resultou não só num acréscimo constante da área plantada, mas também num maior emprego de tecnologia na cultura da uva, gerando assim um aumento na produtividade (IBGE, 2011).

A expansão da viticultura brasileira tem levado os produtores cada vez mais a se adequarem às novas técnicas e manejo da cultura, sobretudo com uso de tecnologias envolvendo os tratos culturais, evidenciando neste caso a realização de podas em diferentes épocas. Estas podem ser determinantes em uma safra, uma vez que é a partir da poda que se inicia o ciclo produtivo da videira (SILVA, et al., 2006). Nesse contexto o emprego de diferentes técnicas de podas pode proporcionar além da melhora da sanidade da planta, melhor desenvolvimento da planta, maior qualidade de frutos e aumento no número de safras por ano. Para uma boa produção de frutos no mesmo ano e nos subseqüentes, é importante haver bom crescimento vegetativo durante a primeira parte da fase de crescimento, onde o período de alongamento dos ramos é, especialmente, muito sensível aos déficits hídricos (DOORENBOS; KASSAN, 1994).

$\mathrm{O}$ primeiro surto de crescimento dos ramos se deve exclusivamente à quantidade de reservas mobilizadas, sendo o movimento dos assimilados essencialmente em direção à ponta dos ramos (HIDALGO, 2002). Nesse estádio as videiras dependem de carboidratos e compostos nitrogenados armazenados em ramos e principalmente raízes (POMMER; PASSOS, 1990). As novas brotações dependem das reservas do ciclo anterior até atingirem aproximadamente, 50\% de seu tamanho, quando passam a exportar mais material fotossintetizado do que importar reservas (GIOVANNINI, 1999).

O segundo tempo de crescimento é dependente dos órgãos verdes (principalmente as folhas), que transformam a seiva bruta em seiva elaborada, proporcionando o crescimento dos brotos (SCARPARE, 2007). À medida que aumenta a temperatura, o crescimento e a elongação do broto são cada vez mais rápidos, atingindo o seu auge em três a quatro semanas. Como os ramos das videiras não possuem gemas terminais, havendo condições favoráveis, o seu crescimento não cessa (GIOVANNINI, 1999).

A uva Niagara Rosada é a cultivar com predomínio absoluto no estado de São Paulo, sendo conduzida em sistemas de espaldeiras com uma densidade que varia de 5000 a 6000 plantas por hectare. O seu período de colheita é realizado entre o fim de novembro e início de janeiro, podendo haver uma segunda colheita entre os meses de maio e junho. Essa segunda produção é caracterizada pela poda realizada no segundo fio da espaldeira, nos meses de janeiro e fevereiro e é conhecida pelos agricultores da região como "Poda Verde" (MORAES, 2003).

Dessa forma, é de grande importância entender as diferenças no desenvolvimento da planta quando essa é submetida a diferentes épocas de poda, pois com ciência dessas diferenças o produtor pode programar suas atividades de forma otimizada, melhorando de uma forma geral o rendimento da cultura.

Assim, o presente trabalho teve como objetivo comparar o desenvolvimento da videira Niagara Rosada podada em diferentes épocas.

\section{MATERIAL E MÉTODOS}

$\mathrm{O}$ experimento foi conduzido em área do Departamento de Produção Vegetal, da ESALQ-USP no município de Piracicaba- 
SP. O tipo climático da região segundo a classificação de Köppen é Cwa (tropical de altitude).

Foi utilizada a uva de mesa, (Vitis labrusca) cultivar Niagara Rosada, em porta enxerto "IAC 766 Campinas", podada em diferentes épocas: a) $\mathrm{Na}$ poda de produção de inverno, ou poda seca, executada no fim do inverno (fase de mobilização de reservas). Quando podada nessa época a colheita dos frutos ocorre no fim da primavera e no começo do verão. Nesse ciclo de produção é realizada uma poda curta (entre uma e duas gemas). O desenvolvimento inicial da videira ocorre em época com baixa umidade relativa (UR) e temperaturas amenas; a maturação e a colheita dos frutos ocorrem em época com temperaturas elevadas e alta UR; b) A poda de produção de verão, ou poda verde, é realizada durante a fase de acúmulo de reservas, e a colheita ocorre no final do outono e começo do inverno. Essa poda de produção é longa, três a quatro gemas. Esse ciclo de produção é caracterizado por apresentar alta UR e temperaturas elevadas no início do desenvolvimento das plantas e temperaturas amenas e baixa UR no período de colheita.

Foram realizadas duas podas no ano agrícola de 2010/2011, sendo a poda de inverno realizada em 4 de agosto de 2010, e a poda de verão realizada em 28 de janeiro de 2011.

O delineamento estatístico foi de blocos ao acaso, com 4 blocos, sendo que cada bloco era representado por uma planta. Em cada bloco foram marcados entre 7 e 8 ramos, totalizando 30 unidades experimentais, sendo cada ramo foi numerado de 1 a 30 . O estudo estatístico foi baseado na comparação de médias (Teste de Tukey) das variáveis abaixo nos dois tratamentos (poda de inverno e poda de verão), utilizando o programa estatístico SAS. O nível de significância adotado foi de $5 \%$.
Em cada uma das unidades experimentais, para ambas as épocas de poda, foram analisadas as seguintes variáveis: a) Comprimento dos ramos em cada período do ciclo produtivo e final; b) Velocidade média do crescimento dos ramos em cada período do ciclo produtivo.

Foram considerados os ciclos produtivos (a e b) e os períodos (c a f): a) Poda à Colheita; b) Brotação à Colheita; c) Poda à Brotação (Consumo de reservas); d) Brotação ao Florescimento (Consumo de reservas); e) Florescimento ao Início da maturação dos frutos (Auto-suficiência); f) Início da maturação dos frutos à Colheita (Acúmulo de reservas);

O cálculo da velocidade de crescimento média foi realizado através da equação 1: $\mathrm{Vm}=(\mathrm{Cf}-\mathrm{Ci}) /(\mathrm{tf}-\mathrm{ti}) . \mathrm{Em}$ que $\mathrm{Vm}$ representa a velocidade média em centímetros por dia, $C i$ representa o comprimento inicial, em centímetros, do ramo, $C f$ o comprimento final, $t i$ a data inicial do período em dias após a poda e if a data final do período em dias após a poda.

\section{RESULTADOS E DISCUSSÃO}

A primeira variável dependente analisada foi o comprimento final dos ramos em cada período estudado. A análise da variância da variável, em ambos os tratamentos está demonstrada na Tabela 1.

As médias em centímetros, obtidas em cada tratamento para cada período dos ciclos produtivos analisado se encontram na Tabela 2.

No período compreendido entre a poda e a brotação não há crescimento de ramos, de forma que não houve resultado para ser tabulado e analisado.

No período compreendido entre a Brotação e o Florescimento foi observado para o tratamento de poda de inverno um comprimento médio de ramos superior ao encontrado no tratamento de poda de verão. 
Tabela 1. Média, desvio padrão, coeficiente de variação e coeficiente de determinação do comprimento final dos ramos, nos tratamentos de poda de produção de inverno e verão.

\begin{tabular}{ccccc}
\hline Período & Média $(\mathrm{cm})$ & $\mathrm{DP}(\mathrm{cm})$ & $\mathrm{CV}$ & $\mathrm{R}^{2}$ \\
\hline \hline Poda - Brotação & 0,000 & 0,000 & 0,000 & 0,000 \\
Brotação - Florescimento & 40,415 & 14,132 & 34,968 & 0,549 \\
Florescimento - Início da Maturação & 85,636 & 53,206 & 62,128 & 0,706 \\
Início da Maturação - Colheita & 0,000 & 0,000 & 0,000 & 0,000 \\
\hline Ciclo Poda - Colheita & 127,190 & 47,381 & 37,252 & 0,658 \\
Ciclo Brotação - Colheita & 127,190 & 47,381 & 37,252 & 0,658 \\
\hline
\end{tabular}

DP - desvio padrão; $C V$ - coeficiente de variação; $\mathrm{R}^{2}$ - coeficiente de determinação.

Tabela 2. Média dos comprimentos finais dos ramos, em centímetros, em cada período e ciclos produtivo nos tratamentos de poda de produção de inverno e verão.

\begin{tabular}{ccc}
\hline Período & Poda de Inverno $(\mathrm{cm})$ & Poda de Verão $(\mathrm{cm})$ \\
\hline \hline Poda - Brotação & 0,00 & 0,00 \\
Brotação - Florescimento & $54,00 \mathrm{~A}$ & $27,86 \mathrm{~B}$ \\
Florescimento - Início da Maturação & $97,46 \mathrm{~A}$ & $73,82 \mathrm{~B}$ \\
Início da Maturação - Colheita & 0,00 & 0,000 \\
\hline Ciclo Poda - Colheita & $151,57 \mathrm{~A}$ & $102,81 \mathrm{~B}$ \\
Ciclo Brotação - Colheita & $151,57 \mathrm{~A}$ & $102,81 \mathrm{~B}$ \\
\hline
\end{tabular}

As médias seguidas de mesma letra no sentido horizontal não diferem estatisticamente entre si, ao nível de 5\% de probabilidade pelo teste de Tukey.

Esses dados mostram a influência da época de poda no crescimento inicial, de forma que vários fatores podem estar envolvidos nesse fluxo vegetativo inicial, como o nível de reservas, o que observou Scarpare Filho e Watanabe (2004).

Quando observa-se o período entre o Florescimento e o Início da Maturação dos Frutos o tratamento de poda de inverno foi novamente superior ao encontrado na poda de verão. Nesse período aconteceu a maior parte do crescimento (64\% na poda de inverno e $72 \%$ na poda de verão).

A partir do Início da maturação dos frutos, conhecida como "veraisson", não foi observado crescimento vegetativo dos ramos, de forma que estes mantiveram como comprimento final o mesmo observado no início dessa fase. isso ocorre em grande parte devido ao fato de que a partir desse ponto a planta passa a direcionar seus fotossintetizados em direção às estruturas de reserva, de modo que as pontas de crescimento (gemas apicais) deixam de ser um dreno significante.

Cada cepa possui uma capacidade de crescimento de suas brotações que é dependente da expansão de seu sistema radicular, do estado dos vasos condutores e do nível de reservas dos órgãos ativos sendo elevada em plantas jovens, até 15-20 anos e diminuindo com a idade. Também é dependente da espécie, da cultivar e da combinação com o porta-enxerto. Além disso, o viticultor pode intervir sobre o crescimento, atuando sobre o microclima das folhas, posição, número e comprimento dos ramos de poda, fertilidade do solo e desponte de ramos (REYNIER, 2003).

Quando se analisa todo o período compreendido entre a Brotação e a Colheita pode-se ter uma visão mais ampla de como ocorreu o desenvolvimento do comprimento final dos ramos. Para a poda de inverno, 
durante o período compreendido entre a Brotação e a Colheita, foi encontrada uma média de comprimento de ramos significantemente superior à encontrada na poda de verão.

No período de Poda a Colheita, no que tange o comprimento final de ramos, foram encontrados exatamente os mesmos resultados do período da Brotação a Colheita, pelo fato de não haver crescimento entre a poda e a brotação.

A próxima variável dependente analisada foi a velocidade média de crescimento dos ramos em cada período estudado. A análise da variância da variável, em ambos os tratamentos está demonstrada na Tabela 3.

As médias em centímetros por dia, obtidas em cada tratamento para cada período analisado se encontram na Tabela 4.

No período compreendido entre a Poda e a Brotação dos ramos não há crescimento vegetativo, de forma que a velocidade de crescimento é nula em ambas as épocas de poda, também não havendo análise estatística.

No período entre a Brotação e o Florescimento a média de velocidade de crescimento dos ramos, em centímetros por dia, foi superior no tratamento de poda de inverno à encontrada na poda de verão. Em ambos os tratamentos essa foi a fase com maior velocidade média de crescimento, de forma que fica claro que as pontas de crescimento (gemas apicais) constituem o principal dreno, e que no caso consomem basicamente as reservas acumuladas do ciclo anterior. Uma explicação para a diferença da velocidade é exatamente o tamanho dessas reservas, já que na poda de inverno houve mais tempo para que a planta pudesse armazenar reservas anteriormente à brotação, e por sua vez para a poda de verão o tempo de armazenamento de reserva foi substancialmente menor.

No período do Florescimento ao Início da maturação dos frutos, para a poda de inverno, a velocidade média de crescimento dos ramos em centímetros por dia foi novamente superior no tratamento de poda de inverno do que no tratamento de poda de verão. Nesse período a velocidade foi bastante inferior ao observado nos outros períodos estudados, pois a partir do florescimento aparecem outros importantes drenos na planta, os frutos, de forma que a partição de fotossintetizados muda e as pontas de crescimento acabam tendo menos energia para se desenvolver.

O período normal para utilização de carboidratos dos ramos, braços e esporões, ocorre a partir da brotação até próximo ao florescimento, quando a taxa de alongamento dos ramos geralmente começa a diminuir consideravelmente: a época exata pode variar muito de vinhedo para vinhedo e depende de muitos fatores, como umidade do solo, clima (temperatura, luz, umidade etc.), fertilidade do solo (especialmente nitrogênio), produtividade da cultura e variedade. Enquanto durar o alongamento dos ramos em taxas rápidas, a acumulação de carboidratos, será retardada (ASSIS et al., 2012).

Como analisado na variável anterior, não houve crescimento vegetativo durante o Início da maturação dos frutos até a Colheita, de forma que a velocidade de crescimento de ramos nesse período foi nula.

É importante lembrar que a partir da lignificação dos ramos e do início da maturação os principais drenos passam a ser as partes de armazenamento da planta, principalmente os frutos e as raízes, a segunda após a colheita. Esta é a fase denominada acúmulo de reservas que termina naturalmente com a queda das folhas e elevação dos níveis de reservas das raízes.

Quando é analisado o ciclo da Brotação até a Colheita fica mais clara a diferença entre os tratamentos. Na poda de inverno a velocidade de crescimento dos ramos, em centímetros por dia foi de 1,25. 
Tabela 3. Média, desvio padrão, coeficiente de variação e coeficiente de determinação da velocidade média de crescimento de ramos nos tratamentos de poda de produção de inverno e verão.

\begin{tabular}{ccccc}
\hline Período & Média (cm/dia) & $\mathrm{DP}$ & $\mathrm{CV}$ & $\mathrm{R}^{2}$ \\
\hline \hline Poda - Brotação & 0,000 & 0,000 & 0,000 & 0,000 \\
Brotação - Florescimento & 1,909 & 0,739 & 38,728 & 0,252 \\
Florescimento - Início da Maturação & 1,116 & 0,723 & 64,766 & 0,712 \\
Início da Maturação - Colheita & 0,000 & 0,000 & 0,000 & 0,000 \\
\hline Ciclo Poda - Colheita & 0,917 & 0,341 & 37,193 & 0,659 \\
Ciclo Brotação - Colheita & 1,052 & 0,385 & 36,576 & 0,678 \\
\hline
\end{tabular}

DP - desvio padrão; CV - coeficiente de variação; $\mathrm{R}^{2}$ - coeficiente de determinação.

Tabela 4. Média da velocidade de crescimento de ramos, em centímetros por dia, em cada período do ciclo produtivo, em ambas as épocas de poda.

\begin{tabular}{ccc}
\hline Período & Poda de Inverno & Poda de Verão \\
\hline \hline Poda - Brotação & 0,0000 & 0,0000 \\
Brotação - Florescimento & $2,0769 \mathrm{~A}$ & $1,7410 \mathrm{~B}$ \\
Florescimento - Início da Maturação & $1,3924 \mathrm{~A}$ & $0,8390 \mathrm{~B}$ \\
Início da Maturação - Colheita & 0,0000 & 0,0000 \\
\hline Ciclo Poda - Colheita & $1,0984 \mathrm{~A}$ & $0,7350 \mathrm{~B}$ \\
Ciclo Brotação - Colheita & $1,2500 \mathrm{~A}$ & $0,7980 \mathrm{~B}$ \\
\hline
\end{tabular}

As médias seguidas de mesma letra no sentido horizontal não diferem estatisticamente entre si, ao nível de 5\% de probabilidade pelo teste de Tukey.

Já na poda de verão, a velocidade de crescimento dos ramos foi de 0,7980 centímetros por dia. De acordo com a análise estatística, a $5 \%$ de significância, os tratamentos foram considerados diferentes.

Com isso se pode afirmar que, no experimento, de uma forma geral a velocidade de crescimento na poda de inverno é mais elevada do que na poda de verão.

No período de poda a colheita, de forma semelhante ao período de Brotação a Colheita, há a possibilidade de analisar o ciclo como um todo. Porém nesse caso é incluído o período em que ainda não há ramos, de forma que as velocidades médias são inferiores às encontradas no item acima.

A velocidade média de crescimento dos ramos em centímetros por dia encontrada para a poda de inverno no período supracitado foi de 1,0984. Já para a poda de verão a velocidade média de crescimento dos ramos foi de 0,7350 centímetros por dia. $\mathrm{O}$ que corrobora com a afirmação de que, para esse experimento, a velocidade de crescimento da poda de inverno foi sempre superior a observada na poda de verão.

\section{CONCLUSÃO}

As plantas podadas no inverno apresentam maiores velocidades médias de crescimento e tamanho de ramos para os ciclos produtivos (Poda à Colheita e Brotação à Colheita) e nos períodos compreendidos neles do que plantas podadas no verão.

\section{REFERÊNCIAS BIBLIOGRÁFICAS}

ASSIS, J.A.; LIMA FILHO, J.M.; LIMA, M.A.C. Fisiologia da Videira. Embrapa 
Semi-Árido. 27p. 2012. Disponível em http://www.alice.cnptia.embrapa.br/bitstre am/doc/154513/1/OPB1175.pdf. Acesso em: 17 maio2012.

DOORENBOS, J; KASSAN, A.H. Efeito da água no rendimento das culturas. (FAO. Estudos. Irrigação e Drenagem 33) Campina Grande: UFPB, 1994. 306 p.

GIOVANNINI, E. Produção de uvas para vinho, suco e mesa. Porto Alegre: Renascença, 1999. 364p.

HIDALGO, L. Tratado de viticultura general. 3.ed. Madrid: Mundi-prensa, 2002. 1235p.

INSTITUTO BRASILEIRO DE GEOGRAFIA E ESTATÍSTICA (IBGE). Disponível em http://www.sidra.ibge.gov.br/bda/Tabela/l istabl.asp? $\mathrm{c}=1613 \& \mathrm{z}=\mathrm{p} \& \mathrm{o}=18$. Acesso em 04 out 2011.

MORAES, A.L. Produção da Videira 'Niagara Rosada' em Função da Desfolha Após a Colheita. 2003 67P. Dissertação (Mestrado de Agronomia) Escola Superior de Agricultura "Luiz de Queiroz", Universidade de São Paulo, Piracicaba. 2003

POMMER, C.V.; PASSOS, I.R.S. Fisiologia da videira: como produz açúcar uma videira? Campinas: Instituto Agronômico de Campinas, 199051 p. (IAC. Documento Técnico, 20).

REYNIER, A. Manual de viticultura. 6. ed. Madrid: Mundi-Prensa, 2003. 497p.

SCARPARE, F. V. Determinação de índices biometeorológicos da videira 'Niagara Rosada' (Vitis labrusca L.) podada em diferentes épocas e fases do ciclo vegetativo. 77 p. 2007. Dissertação
(Mestrado em Agronomia) - Escola Superior de Agricultura "Luiz de Queiroz", Universidade de São Paulo, Piracicaba. 2007.

SCARPARE FILHO, J.A.; WATANABE, A.T. Relação entre os teores de carboidratos solúveis em raízes de videira e os estádios fenológicos, em dois ciclos de produção. In: SIMPÓSIO DE VITIVINICULTURA DO ALENTEJO, 6., 2004. Évora, Portugal, 2004. Anais... Évora, Portugal, 2004. p 199-209.

SILVA, R.P.da; DANTAS, G. G.; NAVES, R. Veloso; CUNHA, M. G. da. Comportamento fenológico de videira, cultivar Patrícia em diferentes épocas de poda de frutificação em Goiás. Bragantia [online], v.65, n.3, p. 399-406, 2006.

SILVEIRA, J.; GALESKAS, H.; TAPETTI, R.; LOURENCINI; I. Quem é o consumidor de frutas e hortaliças. Hortifruti Brasil, CEPEA/ESALQ-USP. p 8-23. Julho de 2011. 